\title{
IMPLEMENTASI PROGRAM KELUARGA HARAPAN TERHADAP PENINGKATAN KESEJAHTERAAN MASYARAKAT MISKIN DI KECAMATAN TELLU LIMPOE KABUPATEN SIDENRENG RAPPANG
}

\author{
1)Nisra, 2)Andi Uceng, ${ }^{3)}$ Sapri, ${ }^{4}$ Syahrir L. \\ Fakultas IImu Sosial dan IImu Politik Universitas Muhammadiyah Sidenreng Rappang \\ 431721040.nisra@gmail.com \\ andiuceng@yahoo.com \\ sapritajuddin3@gmail.com \\ syahrir.lau00@gmail.com
}

\begin{abstract}
Abstrak
Tujuan penelitian ini adalah untuk mengetahui dampak implementasi kebijakan program keluarga harapan terhadap peningkatan kesejahteraan masyarakat miskin di Kecamatan Tellu Limpoe, serta faktor-faktor yang mempengaruhi dampak kebijakan program keluarga harapan terhadap peningkatan kesejahteraan masyarakat miskin. di Kecamatan. Tellu Limpoe. Populasi dalam hal ini adalah 1049 jiwa, sedangkan pengambilan sampel yang digunakan yaitu nonprobability samplin dengan menggunakan jenis penelitian deskriptif kuantitatif dan pengumpulan data meliputi observasi, wawancara, dokumentasi, angket, dan studi pustaka. Metode analisis data yang digunakan adalah uji kualitas data, metode regresi dan pengujian hipoteseis dan sakalalikert dengan menggunakan tabel frekuensi Hasil penelitian menunjukkan implementasi kebijakani program keluarga harapan terhadap peningkatan kesejahteraan masyarakat miskin di Kecamatan Tellu Limpoe Kabupaten Sidenreng Rappang dengan nilai $77.8 \%$ dalam kategori baik, sedangkan faktor yang mempengaruhi implemetasi kebijakan program keluarga harapan terhadap peningkatan kesejahteraan masyarakat miskin di Kecamatan Tellu limpoe 60.4\%. Implementasi Kebijakan program keluarga harapan memiliki pengaruh signifikan sebesar $60.4 \%$ terhadap kesejahteraan masyarakat miskin di Kecamatan Tellu Limpoe Kabupaten Sidenreng Rappang.
\end{abstract}

Kata Kunci : Implementasi, kesejahteraan masyarakat.

\begin{abstract}
The purpose of this study was to determine the impact of the implementation of the policy of the hopeful family program on improving the welfare of the poor in Tellu Limpoe District, as well as the factors that influence the impact of the policy of the hopeful family program on the improvement of the welfare of the poor. in the District. Tellu Limpoe. The population in this case is 1049 people, while the sampling used is non-probability sampling using quantitative descriptive research and data collection includes observations, interviews, documentation, questionnaires, and literature studies. The data analysis method used is data quality test, regression method and hypothesis testing and sakalalikert using a frequency table. The results showed the implementation of the policy of the family program of hope to improve the welfare of the poor in Tellu Limpoe District, Sidenreng Rappang Regency with a value of $77.8 \%$ in the good category, while factors that influence the implementation of the policy of the family program of hope to improve the welfare of the poor in Tellu Limpoe District 60.4\%. The implementation of the Hope Family Program policy has a significant effect of $60.4 \%$ on the welfare of the poor in Tellu Limpoe District, Sidenreng Rappang Regency.
\end{abstract}

Keywords: Implementation, community welfare. 


\section{A. PENDAHULUAN}

Kesejahteraan adalah suatu tata kehidupan dan penghidupan sosial, material, maupun spiritual yang diliputi rasa keselamatan, kesusilaan dan ketentraman lahir batin yang memungkinkan setiap warga negara untuk mengadakan usaha-usaha pemenuhan kebutuhan jasmani, rohani dan sosial yang sebaik-baiknya bagi diri, rumah tangga serta masyarakat. (Sunarti, 2012). Kesejahteraan merupakan sejumlah kepuasan yang yang diperoleh seseorang dari hasil mengkonsumsi pendapatan yang diterima, namun tingkatan dari kesejahteraan itu sendiri merupakan sesuatu yang bersifat relative karena tergantung dari besarnya kepuasan yang diperoleh dari hasil mengkonsumsi pendapatan tersebut. Keterkaitan antara konsep kesejahteraan dan konsep kebutuhan adalah dengan terpenuhinya kebutuhan-kebutuhan tersebut, maka seseorang sudah dinilai sejahtera, karena tingkat kebutuhan tersebut secara tidak langsung sejalan dengan indikator kesejahteraan (Pramata, dkk 2012). Sementara itu Pemerintah Republik Indonesia telah menerapkan kebijakan terkait Kesejahteraan Sosial dalam UU 11 tahun 2009 tentang Kesejahteraan Sosial adalah kondisi terpenuhinya kebutuhan material, spiritual, dan sosial warga negara agar dapat hidup layak dan mampu mengembangkan diri, sehingga dapat melaksanakan fungsi sosialnya. Pasal 34 ayat (1) Undang-Undang Dasar Negara Republik Indonesia Tahun 1945 mengamanatkan kewajiban negara untuk memelihara fakir miskin dan anak terlantar. Kesejahteraan masyarakat tidak lepas dari pembahasan mengenai kemiskinan, karena aspek ini saling berkaitan dan mempengaruhi. Kemiskinan didefinisikan sebagai ketidakmampuan masyarakat untuk memenuhi kebutuhan dasar seperti sandang, pangan, papan, serta kesehatan dan pendidikan.. Keluarga atau masyarakat kalangan menengah ke bawah, Masyarakat atau Keluarga miskin dengan pendapatan rendah kesulitan untuk memenuhi kebutuhan makan sehari-hari, bahkan tak jarang anakanak dari kalangan keluarga miskin tidak bisa mengenyam pendidikan dikarenakan tuntutan untuk ikut serta mencari uang demi membantu kebutuhan hidup keluarga. Kemiskinan menjadi penyebab utama timbulnya suatu kriminalitas di negara-negara yang masih berkembang, sehingga
e-ISSN 2723-0201 mengupayakan program perlindungan sosial untuk mengentaskan kemiskinan masyarakat melalui bantuan sosial, jaminan sosial ataupun melalui regulasi mengenai standar minimum upah pekerja yang diharapkan bisa mengurangi atau mengentaskan kemiskinan.

Program-program yang dilaksanakan dalam upaya pengentasan kemiskinan belum memberikan dampak yang signifikan, sehingga tujuan pembangunan nasional yang terkait dengan masalah pemerataan kesejahteraan masyarakat tetap menjadi masalah yang persisten. Alhasil, pemerintah meluncurkan Program Keluarga Harapan $(\mathrm{PKH})$ untuk mengatasi masalah kemiskinan. Dalam kaitan ini, pelaksanaan Program Keluarga Harapan (PKH) di Kecamatan Tellu Limpoe didasari oleh tingginya jumlah rumah tangga miskin.

Mempercepat dan menangani
masalah kemiskinan, pemerintah mengeluarkan beberapa kebijakan yang berkaitan dengan bantuan sosial maupun perlindungan sosial. Peraturan Presiden No. 54 Tahun 2005 tentang Tim Koordinasi Penanggulangan Kemiskinan yang diubah menjadi Peraturan Presiden No. 13 Tahun 2009 yang bertugas untuk mengurangi jumlah penduduk miskin di seluruh wilayah indonesia. Kemudian terbitlah Instruksi Presiden No. 3 Tahun 2008 tentang Pelaksanaan Program Bantuan Langsung Tunai atau BLT untuk Rumah Tangga Sasaran (RTS). Selain BLT, pemerintah juga mengeluarkan kebijakan berupa Raskin (Beras Miskin) dan Jaminan Kesehatan Masyarakat (Jamkesmas) yang dilandaskan dari Peraturan Kementrian Kesehatan No. 40 Tahun 2012. Namun pada saat ini ketiga program bantuan sosial tersebut diganti dengan Program Keluarga Harapan $(\mathrm{PKH})$ dengan sasaran penerima dari kalangan masyarakat ekonomi lemah sesuai kriteria tertentu atau lebih dikenal dengan KPM (Keluarga Penerima Manfaat). Untuk merealisasikan program bantuan sosial Program Keluarga Harapan (PKH) maka pemerintah mengeluarkan Peraturan Presiden No. 166 Tahun 2014 tentang Program Percepatan Penanggulangan Kemiskinan dan Peraturan Kementrian Sosial No. 10 Tahun 2017 tentang Program Keluarga Harapan (PKH). Program Keluarga Harapan (PKH) adalah bantuan sosial yang bertujuan untuk mempertahankan kehidupan 
dalam kebutuhan dasar termasuk di dalamnya ekonomi, pendidikan, dan kesehatan. Selain itu PKH juga bertujuan untuk memberdayaaan keluarga agar bisa keluar dari kemiskinan dengan meningkatkan kesehatan dan mendorong anak bersekolah KKS (Kartu Keluarga Sejahtera) dan KIP adalah dua program bantuan sosial yang termasuk dalam $\mathrm{PKH}$ (Kartu Indonesia Pintar). Masyarakat penerima Program Keluarga Harapan (PKH) berhak mendapatkan bantuan berupa dana simpanan e-money berbentuk kartu yang bisa diambil sendiri melalui mesin atm yang terdekat dengan tempat tinggalnya, selain mendapatkan bantuan dana masyarakat yang memegang KKS juga mendapatkan BPNT (Bantuan Pangan Non Tunai) berupa sembako yang bisa diambil setiap bulan melalui RT/RW yang sudah ditunjuk oleh aparat desa.. Untuk KIP khusus ditujukan bagi masyarakat miskin yang mempunyai anak sekolah baik dari tingkat SD maupun SMA/Sederajat.

Masalah yang terus menjadi fenomenal dibelahan dunia, khususnya di Indonesia yaitu masalah kemiskinan. Selain karena kemiskinan sudah ada sejak lama dan sampai sekarang masih hadir ditengahtengah hidup kita, gejala yang ada juga semakin dirasakan. Masalah kemiskinan juga sejalan karena tingkat kesejahteraan rakyat indonesia masih jauh dibawah Standar hidup di negara maju. Berdasarkan data Badan Pusat Statistik (BPS) tingkat kemiskinan indonesia per Maret 2019 tercatat sebesar 9,41\%. (Tandioga, 2016).

Amanat dari pembukaan Undangundang Dasar 1945 alinea ke empat yaitu menciptakan kesejahteraan bagi seluruh rakyat Indonesia serta mencerdaskan kehidupan bangsa. Dalam rangka mengurangi masalah kesejahteraan masyarakat $\mathrm{Di}$ Indonesia, pemerintah melaksanakan berbagai program dan insentif untuk mengentaskan kemiskinan melalui Kementerian Sosial.. Pemerintah indonesia menerapkan kebijakan Program Keluarga Harapan yang diterapkan dalam Peraturan Menteri Sosial Nomor 1 tahun 2018 tentang Program Keluarga Harapan (PKH). Kabupaten Sidenreng Rappang merupakan salah satu kabupaten yang terletak di provinsi Sulawesi Selatan, juga menerapkan Program Keluarga Harapan $(\mathrm{PKH})$ untuk membantu masyarakat. Adapun jumlah penduduk miskin di Sidenreng Rappang mengalami peningkatan dari tahun 2019 ke tahun 2020 sebanyak 0,26\% (Sumber:BPS Kab.Sidrap). Hal ini berarti tingkat kemiskinan mengalami peningkatan dari beberapa persen. Maka dari itu, Program Keluarga Harapan (PKH) harus dijalankan sesuai dengan peraturan yang berlaku. Untuk keberhasilan Program Keluarga Harapan (PKH) tersebut dapat dilihat dari implementasi kebijakan pelaksanaan peraturan terkait yakni peraturan menteri sosial nomor 1 tahun 2018 tentang program keluarga harapan.

Pelaksanaan Program Keluarga Harapan (PKH) khususnya di Kecamatan Tellu Limpoe Kabupaten Sidenreng Rappang ada beberapa identifikasi masalah antara lain :Data yang digunakan untuk penerima Program Keluarga Harapan (PKH) masih menggunakan data lama sehingga banyak yang tidak tepat sasaran, Kurangnya pembinaan dan pemberdayaan keluarga yang dilakukan oleh Pelaksana Program Keluarga Harapan (PPKH), Perbedaan dana yang diterima cukup besar sehingga menimbulkan kecemburuan sosial diantara Keluarga Penerima Manfaat (KPM), Angka kemiskinan yang masih cukup tinggi di kecamatan Tellu Limpoe. Berdasarkan fenomena yang ada diatas maka Riant (2012: 707-710) mengemukakan bahwa terdapat lima "tepat" yang perlu dipenuhi dalam hal keefektifan implementasi kebijakan. Tepat kebijakan, Tepat pelaksananya, Tepat target, Tepat lingkungan, Tepat proses. Permasalahan yang di temukan di atas maka penulis menentukan judul penelitian implementasi program keluarga harapan terhadap peningkatan kesejahteraan masyarakat miskin di Kecamatan Tellu Limpoe Kabupaten Sidenreng Rappang.

Implementasi adalah rangkaian aktivitas dalam menghantarkan suatu pada suatu kebijakan masyarakat. hal tersebut dapat membawa hasil sebagaimana mestinya Syaukani dkk (2004:295). Dari perspektif ini, jelas bahwa proses implementasi yang sebenarnya memerlukan lebih dari sekedar perilaku administratif yang bertanggung jawab dalam pelaksanaan suatu program dan akan menimbulkan suatu ketaatan diri kelompok sasaran, melainkan kekuatan politik, ekonomi, dan sosial yang dapat mempengaruhi perilaku semua pihak yang terlibat dalam menentukan arah tujuan 
kebijakan yang dapat diwujudkan melalui kegiatan pemerintah.

Implementasi adalah tindakan yang dilakukan oleh individu, pejabat pemerintah, atau kelompok untuk mencapai tujuan yang dituangkan dalam keputusan kebijakan.Meter dan Horn dalam Wahab, (2004:65). Berdasarkan hal yang ada diatas maka implementasi merupakan tindakan yang dilakukan oleh individu, pejabat pemerintah diarahakan pada tujuan yang sudah ditentukn secara tertentu. Implementasi merupakan pelaksanaan kebijakan dasar dalam bentuk UU bisa juga berbentuk perintah yang penting seperti keputusan peradilan.

Menurut Daniel Mazmanian dan Paul Sabatier dalam bukunya dalam Leo Agustino (2006:139), kebijakan publik diartikan sebagai pelaksanaan keputusan kebijakan dasar, biasanya berupa undang-undang, tetapi dapat juga berupa perintah, eksekutif penting. keputusan, atau keputusan pengadilan. Biasanya, keputusan mengidentifikasi masalah yang akan ditangani, menyatakan secara eksplisit tujuan atau sasaran yang ingin dicapai, dan mengusulkan berbagai cara untuk menyusun atau mengatur proses implementasi.

Menurut ketiga definisi di atas, implementasi kebijakan mencakup tiga hal: (1) adanya tujuan atau sasaran kebijakan; (2) adanya kegiatan atau kegiatan untuk mencapai tujuan; dan (3) adanya kegiatan atau kegiatan untuk mencapai tujuan dan (3) adanya aktivitas sebagai hasilnya. Implementasi adalah suatu proses dinamis dimana para pelaksana kebijakan melakukan suatu kegiatan atau kegiatan untuk mencapai suatu hasil yang sesuai dengan tujuan atau sasaran kebijakan. Implementasi

sebagaimana telah dikemukakan sebelumnya, dilakukan dalam upaya mencapai tujuan kebijakan. Mencapai tujuan tidak diragukan lagi terkait dengan efektivitas. Dunn (2003:429) mengemukakan bahwa efektivitas berkenaan dengan apakahsuatu alternatif mencapai hasil (akibat) yang diharapkan, atau mencapai tujuan dari diadakannya tindakan.

Soewarno Handayaningrat (1990:16) mengutip definisi efektifitas $\mathrm{H}$. Emerson, yang menyatakan bahwa efektivitas adalah ukuran pencapaian tujuan atau sasaran yang telah ditentukan sebelumnya. Sejauh mana implementasi kebijakan dilakukan untuk mencapai tujuan kebijakan yang diharapkan berkaitan dengan efektivitas implementasi kebijakan. Menurut Riant (2012: 707-710), ada lima "tepat" yang harus dipenuhi agar implementasi kebijakan dapat efektif.

1. Tepat Kebijakann. Thomas R. Dye dalam (Sri, suwatri: 2009:17-19), mengemukakan bahwa Kebijakan publik didefinisikan sebagai "apa pun yang dipilih pemerintah untuk dilakukan atau tidak dilakukan". Untuk mencapai tujuan negara, pemerintah harus melakukan analisis kebijakan publik dan memilih antara melakukan dan tidak melakukan sesuatu. adalah upaya yang berorientasi pada tujuan, pilihan ini memiliki dampak yang sama dengan keputusan untuk melakukan sesuatu bagi masyarakat.

2. Tepat Pelaksanaannya. Thomas R. Dye, mengemukakan kebijakan publik yaitu sebagai " apapun pilihan pemerintah untuk melakukan atau tidak melakukan sesuatu. Analisis Kebijakan Publik dalam hal upaya mencapai tujuan negara, pemerintah perlu mengambil pilihan langkah tindakan yang dapat berupa melakukan ataupun tidak melakukan sesuatu. Tidak melakukan apapun merupakan suatu kebijakan publik, karena ialah upaya pencapaian tujuan dan pilihan tersebut memiliki dampak yang sama besarnya dengan pilihan langkah untuk melakukan sesuatu terhadap masyarakat.

3. Tepat Target. Menurut Syaukani dkk (2004:95) implementasi merupakan suatu rangkaian aktivitas dalam rangka menghantarkan kebijakan kepada masyarakat sehingga kebijakan tersebut dapat membawa hasil sebagaimana diharapkan.

4. Tepat Lingkungan. Tepat ke empat adalah pengaturan yang tepat Ada dua lingkungan yang paling mempengaruhi kebijakan.

5. Tepat Proses. Terdiri dari tiga proses, salah satunya adalah Policy Acceptance, dimana publik mempersepsikan kebijakan sebagai aturan dan pemerintah memandangnya sebagai tugas yang harus diselesaikan. Adopsi kebijakan terjadi ketika publik menerima kebijakan sebagai aturan dan pemerintah menerimanya sebagaii tugas yang harus diselesaikan. Kesiapan strategis yaitu publik siap melaksanakan atau menjadi bagian dari 
kebijakan dann birokrat siap menjadi pelaksana kebijakan.

Berdasarkan UU No. 11 Tahun 2009 Pasal 34 ayat 1 , kesejahteraan sosial adalah kondisi terpenuhinya kebutuhan material, spiritual, dan sosial warga negara agar dapat hidup layak dan mampu mengembangkan diri, sehingga dapat melaksanakan fungsi sosialnya. Pasal 34 Ayat (1) Undang-undang Dasar Negara Republik Indonesia Tahun 1945 mengamanatkan kewajiban negara untuk memelihara fakir miskin dan anak terlantar. Menurut Friedlander (Fahrudin, 2012: 9) "kesejahteraan sosial adalah suatu sistem yang terorganisasi dari pelayananpelayanan sosial dan lembaga-lembaga, yang bermaksud untuk membantu individuindividu dan kelompok agar mencapai standar kehidupan dan kesehatan yang memuaskan, serta hubungan perorangan dan sosial yang memungkinkan mereka mengembangkan segenap kemampuan dan meningkatkan kesejahteraan petani selaras dengan kebutuhan-kebutuhan keluarga maupun masyarakat".

Kesejahteraan keluarga memiliki dimensi yang dijadikan acuan dalam penelitian kesejahteraan sosial yang Menggunakan fungsi kesejahteraan sosial Friedlander dan Apte (Fahrudin, 2012:12):

1. Fungsii Pencegahan (preventif). Tujuan kesejahteraann sosial adalah untuk memperkuat individu, keluarga, dan masyarakat agar tidak timbul masalah sosial baru. Upaya pencegahan dalam masyarakat transisi difokuskan pada kegiatan yang membantu pembentukan pola baru hubungan sosial dan lembaga sosial.

2. Fungsi Pemulihan (Rehabilitas). Tujuan dari kesejahteraan sosial adalah untuk menghilangkan kondisi cacat fisik, emosional, dan sosial sehingga mereka yang mengalami masalah tersebut dapat berfungsi secara normal di masyarakat.l

3. Fungsi Pengembangan (Development). Kesejahteraan sosial berfungsi untuk berkontribusi secara langsung atau tidak langsung terhadap perkembangan struktur dan sumber daya sosial dalam masyarakat.

4. Fungsi Penunjang (Supportive) Fungsi ini mencakup kegiatan yang membantu pencapaian tujuan sektor atau bidang lain dari layanan kesejahteraan sosial.
Program Keluarga Harapan (PKH) merupakan program perlindungan sosial yang disponsori pemerintah bagi masyarakat. yang berhak menerima bantuan sosial tersebut. Hal ini di dasarkan dari Peraturan Presiden No. 166 Tahun 2014 tentang Program Percepatan Penanggulangan Kemiskinan dalam Pasal 2 ayat 1 dan 2 . Dalam pelaksanaan Program Perlindungan Sosial tersebut presiden menurunkannya dalam Peraturan Menteri Sosial No. 10 Tahun 2017 mengenai Program Keluarga Harapan (PKH) dan untuk meningkatkan efektifitas serta efisiensi dalam pelaksanaan program bantuan sosial program perlindungan sosial tersebut pemerintah menerbitkan, Kartu Keluarga Sejahtera (KKS)

Untuk Keluarga yang menerima bantuan berupa simpanan uang, Kartu Indonesia Pintar (KIP)Untuk Para Pelajar yang menerima bantuan dana sekolah. Program Keluarga Harapan (PKH) bertujuan untuk mengurangi jumlah penduduk miskin, memutus mata rantai kemiskinan, meningkatkan kualitas sumber daya manusia, dan mengubah perilaku yang merugikan kesejahteraan kelompok termiskin. Tujuan ini terkait langsung dengan upaya percepatan pencapaian Millenium Development Goals (MDGs).

Geogre C.Edward III dalam (Subarsono, 2013:90) menamakan model implementasi kebijakan publik dengan Direct and Indirect Impact on Implementation, berikut adalah teori yang mempengaruhi keberhasilan implementasi suatu kebijakan :

1. Komunikasi. Keberhasilan implementasi kebijakan George C. Edward III (Agustino 2008), merupakan bentuk komunikasi Menurutnya, komunikasi akan menentukan keberhasilan pencapaian tujuan dari implementasi kebijakan publik. Ketika pengambil keputusan sudah tahu apa yang akan mereka lakukan, implementasi yang efektif terjadi.

2. Sumber Daya. Menurut George C. Edward III (Agustino 2008), sumber daya merupakan faktor penting lainnya dalam implementasi kebijakan. Indikator sumber daya mencakup beberapa komponen, antara lain Staff, Informasi Fasilitas.

\section{B. METODE PENELITIAN}

Penelitian ini menggunakan penelitian deskriptif kuantitatif untuk memastikan keberadaan variabel bebas, baik pada satu 
atau lebih variabel tanpa membuat perbandingan atau koneksi ke variabel lain. Adapun populasi dalam hal ini adalah seluruh Keluarga Penerima Manfaat di Kecamatan Tellu Limpoe sejumlah 1049 jiwa. sedangkan teknik penarikan sampel menggunakan sampling purposive. Observasi, angket, wawancara, dan studi pustaka digunakan untuk mengumpulkan data, yang kemudian dianalisis menggunakan tabel frekuensi dan SPSS 16 for Windows.

\section{HASIL DAN PEMBAHASAN}

Berdasarakan hasil observasi, koesioner, dan studi pustaka yang informasi tentang responden dapat diperoleh dari kuesioner yang dibagikan kepada mereka implementasii program keluarga harapan terhadap peningkatan kesejahteraan masyarakat miskinn di Kecamatan Tellu

Limpoe kabupaten Sidenreng Rappang. Dari Penelitian tersebut menghasilkan informasi yang dapat digunakan sebagai bahan penelitian dan kesimpulan implementasii program keluarga harapan terhadap peningkatan kesejahteraan masyarakat miskin di Kecamatan Tellu Limpoe Kabupaten Sidenreng dapat dijabarkan sebagai berikut:

1. Implementasi kebijakan Program Keluarga Harapan (PKH)

Berdasarkan hasil data rekapitulasi kuisioner penelitian yang dilakukan di Kecamatan Tellu Limpoe Kabupaten Sidenreng Rappang, pada implementasi kebijakan program keluarga harapan diperoleh persentase yaitu $77.8 \%$ dengan kategori sangat baik, hal ini menunjukkan bahwa implementasi kebijakan program keluarga harapan yang seharusnya mencapai $100 \%$ namun terdapat $22.2 \%$ persentase yang tidak tercapai. Menurut Meter dan Horn (Wahab,2004:65). Suatu tindakan yang dilakukan oleh individu, pejabat pemerintah, atau keduanya disebut sebagai implementasi. kelompok untuk mencapai suatu tujuan yang dituangkan dalam suatu keputusan kebijakan.. Riant (2012: 707-710) mengemukakan bahwa terdapat limat tepat yang perlu di penuhi dalam implementasi kebijakan yaitu tepat kebijakan, tepat pelaksananya, tepat target, tepat lingkungan, dan tepat proses.

Dlihat dari item kuisioner dalam penelitian diperoleh data responden yang paling tinggi persentasenya adalah tepat
p-ISSN 2302-0970

e-ISSN 2723-0201

kebijakan dengan persentase 90\%. Sedangkan responden terendah adalah tepat target dengan persentase $48 \%$. Dengan melihat hasil persentase terendah dari penjabaran tersebut dapat dikatakan bahwa indikator tepat target memiliki persentase terendah dibandingkan dengan indikator lainnya yang merupakan penghambat implementasi program keluarga harapan sehingga pelaksanaannya tidak mencapai $100 \%$. Hal ini menunjukkan bahwa data penerima bantuan program keluarga harapan yang ada di dinas sosial kurang valid, karena terdapat data masyrakat yang menerima bantuan namun kenyataan sudah termasuk dalam kategori sejahtera, sehingga dapat dikatatakan tidak tepat target atau tidak tepat sasaran.

2. Kesejahteraan Keluarga

Berdasarkan dari data rekapitulasi keusioner penelitian yang dilaksanakan di Kecamatan Tellu Limpoe Kabupaten Sidenreng Rappang, pada kesejehteraan keluarga diperoleh rata-rata persentase yaitu $86.5 \%$ dengan kategori sangat baik, hal ini berarti indikator kesejahteraan keluarga yang seharusnya mencapai 100\% namun masih ada $13.5 \%$ persentase yang tidak tercapai. Menurut Friedlander (Fahrudin, 2012:9) Kesejahteraan sosial adalah sistem pelayanan dan lembaga sosial yang terorganisir yang bertujuan untuk membantu individu dan kelompok dalam mencapai standar hidup dan kesehatan yang memadai serta hubungan individu dan sosial yang memungkinkan mereka untuk mencapai potensi penuh mereka dan meningkatkan kesejahteraan petani berdasarkan kebutuhan rumah tangga dan masyarakat.

Acuan dalam penelitian kesejahteraan keluarga menggunakan fungsi-fungsi kesejahteraan sosial yang diungkapkan oleh Friedlander \& Apte (Fahrudin, 2012 : 12) yaitu fungsi pencegahan, fungsi pemulihan, fungsi pengembangan dan fungsi penunjang. Dilihat dari item kuesioner diperoleh data responden paling tinggi adalah fungsi pemulihan dengan persentase $90 \%$. Sedangkan ada dua data responden yang memiliki persentase terendah yaitu fungsi pengembangan dan fungsi penunjang masing-masih memiliki persentase $84 \%$. Dengan melihat persentase terendah dari penjabaran tersebut dapat dikatakan bahwa indikator fungsi pengembangan dan fungsi pencegahan memiliki persentase terendah 
dibandingkan dengan indikator lainnya yang merupakan faktor penghambat kesejahteraan masyarakat sehingga tidak mencapai $100 \%$. Hal ini menunjukkan bahwa perlunya pengembangan dan penunjangan yang memadai untuk masyarakat kurang mampu.

3. Faktor - faktor Implementasi Program Keluarga Harapan (PKH) terhadap peningkatan kesejahteraan masyarakat di Kecamatan Tellu Limpoe

Berdasarkan hasil rekapitulasi data keusioner pada penelitian yang dilakukan di Kecamatan Tellu Limpoe Kabupaten Sidenreng Rappang diperoleh persentase $60.4 \%$ berpengaruh. George C. Edward III dalam (Subarsono, $2013: 90$ ) penyematan model implementasi kebijakan yang berdampak langsung dan tidak langsung terhadap implementasi Dalam pendekatan ini terdapat dua variabel model yang mempengaruhi faktor keberhasilan implementasi kebijakan, yaitu faktor komunikasi dan sumber daya.. Faktor komunikasi dengan persentase $70.3 \%$ dan faktor sumber daya dengan persentase $50.5 \%$.

\section{KESIMPULAN}

Berdasarkan temuan pembahasan sebelumnya, maka dapat ditarik kesimpulan:

1. Implementasi Kebijakan Program Keluarga Harapan (PKH) terhadap Peningkatan Kesejahteraan Masyrakat di Kecamatan Tellu Limpoe Kabupaten Sidenreng Rappang termasuk dalam ratarata kategori "sangat baik" yaitu $77.8 \%$.

2. Faktor komunikasi yang mempengaruhi implementasi program keluarga harapan terhadap peningkatan kesejahteraan masyrakat $70.3 \%$, faktor sumber daya yang mempengaruhi implemntasi program keluarga harapan terhadap kesejahteraan masyarakat $60.4 \%$.

3. Implementasi Pogram Keluarga Harapan memiliki pengaruh signifikan terhadap peningkatan Kesejahteraan Keluarga sebesar $73 \%$.

\section{E. REFERENSI}

Ahmad, J. (2015). Metode Penelitian Administrasi Publik. Yogyakarta: Gava Media.

Ir. Syofian Siregar, M. (2013). Metode Penelitian Kuantitatif . Jakarta: Kencana.
p-ISSN 2302-0970

e-ISSN 2723-0201

Mulyadi, D. (2016). Studi Kebijakan Publik dan Pelayanan Publik. Bandung: Alfabeta.

Pasolong, H. (2008). Teori Administrasi Publik. Bandung: Alfabeta.

Prof.Dr.H.M. Burhan Bungin, S. M. (2005). Metodologi Penelitian Kuantitatif. Jakarta: Kencana.

Sugiyono, P. D. (2014). Metode Penelitian Kuantitatif Kualitatif Dan R\&D. Bandung: Alfabeta.

Kholif, K. I., Noor, I., \& Siswidiyanto. (2014). Implementasi Program Keluarga Harapan ( PKH ) Dalam Menanggulangi Kemiskinan Di Kecamatan Dawarblandong Kabupaten Mojokerto. Jurnal Administrasi Publik, 2(4), 709-714.

S.Tlonaen, Y., Hardiyanto, W., \& Diahloka, C. (2014). Implementasi Program Keluarga Harapan (Pkh) Untuk Meningkatkan Kesejahteraan Masyarakat Miskin. Jurnal IImu Sosial Dan IImu Politik Universitas Tribhuwana Tunggadewi, 3(1), 42400.

Virgoreta, D. (2015). Implementasi Program Keluarga Harapan (PKH) Dalam Upaya Meningkatkan Kesejahteraan Masyarakat (Studi Pada Desa Beji Kecamatan Jenu, Kabupaten Tuban). None, 3(1), 1-6.

Kholif, K. I., Noor, I., \& Siswidiyanto. (2014). Implementasi Program Keluarga Harapan ( PKH ) Dalam Menanggulangi Kemiskinan Di Kecamatan Dawarblandong Kabupaten Mojokerto. Jurnal Administrasi Publik, 2(4), 709-714.

Kartika Ayu. (2020). Implementasi Program Keluarga Harapan (PKH) Di Desa Pancakarya Kecamatan Ajung Kabupaten Jember. Jurnal Ekonomi Ekuilibrium (JEK), 4(1), 1-16. Retrieved from https://jurnalmahasiswa.unesa.ac.id/in dex.php/publika/article/view/13711

Kholif, K. I. (n.d.). IMPLEMENTASI PROGRAM KELUARGA HARAPAN ( PKH ) DALAM MENANGGULANGI KEMISKINAN DI KECAMATAN 
DAWARBLANDONG KABUPATEN
MOJOKERTO Khodiziah Isnaini Kholif , Irwan Noor , Siswidiyanto. 2(4), 709714.

Utomo, D. (2014). Pelaksanaan Program Keluarga Harapan Dalam Meningkatkan Kualitas Hidup Rumah Tangga Miskin (Studi Pada Unit Pelaksana Program Keluarga Harapan Kecamatan Purwoasri Kabupaten Kediri). Jurnal Administrasi Publik Mahasiswa Universitas Brawijaya, 2(1), 29-34.

Sitorus, G. K. (2013). PENGARUH IMPLEMENTASI PROGRAM KELUARGA HARAPAN TERHADAP KESEJAHTERAAN MASYARAKAT DI KELURAHAN KINILOW KECAMATAN TOMOHON UTARA KOTA TOMOHON. Journal of Chemical Information and Modeling, 01(01), 1689-1699.

Citra Kunia putri dan trisna insan Noor, 2011. (2013). Kesejahteraan Masyarakat. Analisis Pendapatan Dan Tingkat Kesejahteraan Rumah Tangga Petani, 53(9), 1689-1699.

Infitah, N., Sukidin, S., \& Hartanto, W. (2019). Efektivitas Program Keluarga Harapan (Pkh) Di Desa Sumber Kejayan Kecamatan Mayang Kabupaten Jember. JURNAL PENDIDIKAN EKONOMI: Jurnal IImiah IImu Pendidikan, IImu Ekonomi Dan IImu Sosial, 13(2), 103. https://doi.org/10.19184/jpe.v13i2.113 $\underline{46}$

Peraturan Menteri Sosial Republik Indonesia No. 10 Tahun 2017 tentang Program Keluarga Harapan (PKH). Peraturan Menteri Sosial Republik Indonesia No, 10 Tahun 2017 Tentang Program Keluarga Harapan (PKH).

Undang - undang Dasar 1945 